\title{
Distribution Conventionality in the Movie Sector: An Econometric Analysis of Cinema Supply
}

\author{
A.Collins \\ University of Portsmouth \\ A.E. Scorcu* \\ University of Bologna and RCEA \\ R.Zanola* \\ University of Eastern Piedmont and RCEA
}

\begin{abstract}
This paper empirically analyzes the impact of several factors on a 'conventionality index' in the specific context of the cinema exhibition sector. To our knowledge, it is the first time that a standard conventionality index has been constructed for this purpose. Econometric analysis of the determinants of variation in this index provides decision-makers with an empirical focus for analyzing distributional aspects of the movie exhibition market, with particular emphasis on product differentiation. Specifically, (i) do cinemas based in a city area have a different or 'specialized' focus in contrast to cinemas in small towns? Or, (ii) do multiplexes have a different or more specialized focus in comparison with cinemas? To this end, cross-sectional econometric models are estimated to help analyze these effects in three Italian regions for a sample of cinemas covering the 2006 season.
\end{abstract}

JEL classification: C2; D2; Z1.

Key words: movies; conventionality index; supply; Italy.

\footnotetext{
- Department of Economics, University of Portsmouth Business School, Portland Street, Portsmouth P01 3DE, England, e-mail: alan.collins@port.ac.uk

- Department of Economics, University of Bologna, Strada Maggiore 45, I-40125 Bologna, Italy, e-mail: antonello.scorcu@unibo.it; Rimini Center

Department of Public Policy and Public Choice, University of Eastern Piedmont, Corso Borsalino 83, I15100 Alessandria, Italy, e-mail: zanola@sp.unipmn.it
} 


\section{Introduction}

Many studies have explored the extent of product differentiation within arts organizations. Such work has tended to focus on high cultural pursuits such as opera, dramatic theater or symphony orchestra concerts (Neligan, 2006; O’Hagan and Neligan, 2005; Pierce, 2000; Dowd et al 2002). It is typical for these activities to require substantial public financial support and/or substantial corporate sponsorship arrangements. Accordingly, many investigations (typically involving the construction of a 'conventionality index' (CI)) have sought to focus on the extent to which subsidized/sponsored performances disproportionately feature 'safe' or 'established' repertoire and eschew 'new' or 'experimental' work. The hypothesized rationale is that by such a strategy it is thought more likely that continuity of public funding (and/or major corporate sponsorship arrangements) can be secured or renewed. The alternative hypothesis, however, can also be explored. This relates to whether a measure of ‘insulation' from commercial pressures afforded by significant public funding and/or corporate sponsorship can actually foster greater artistic experimentation and radicalism to embrace the 'shock of the new'.

In cinema exhibition, private sector financing overwhelmingly dominates, though there are many publicly supported arts cinemas and in Italy at least, there is also a significant state film distributor working among the private sector film distribution giants. Nevertheless, despite the market orientation, expressions of consumer dissatisfaction regarding the limited extent of offered product differentiation in various towns' and cities' cinemas and multiplexes have arisen (see, for example, Hubbard, 2000, 2002). It is thus of policy interest to explore the extent to which such expressions empirically valid. Decision-making regarding the disbursement of public or sponsorship funding of film products and specialist or art house movie theaters could also be informed by such an evidence base. While there may be much anecdotal chatter and perceptions that movie theaters are showing too many similar films, the degree to which this is truly the case in a given geographical area is an open empirical question.

This is the first paper, to our knowledge, to construct an orthodox conventionality index (CI) in the specific context of cinema (movie theater) exhibition. That said, in the specific context of the Boston metropolitan area, Chisholm, Macmillan and Norman (2007) have developed a related index - a 'similarity index'- in the context of film scheduling. This is used to 
investigate the determinants of strategic product differentiation in the industry as conditioned by contractual constraints. In general they find that product differentiation is inversely related to market size and that more similar film programming is found within movie theaters under common ownership.

This study uses data from three representative Italian regions. Cross-sectional econometric models are estimated to help analyze variation in this CI. By so doing a particular mode of empirical enquiry is enabled to help frame analysis of some distributional aspects of the movie exhibition market. Specifically, (i) do cinemas based in a city area have a different or more 'specialized' focus in contrast to cinemas in small towns? Or, (ii) do multiplexes have a different or more specialized focus in comparison with cinemas? While differences in consumers' movie-going behavior has been analyzed with respect to multiplex and nonmultiplex movie theaters (Collins et al., 2005), supply-side differences in terms of movie distribution conventionality have not been similarly explored.

The paper is organized in the following manner. The next section explores some of the economics of product differentiation that can inform work on movie exhibition conventionality and presents a guiding theoretical framework to this study. Background on the movie exhibition sector in Italy is then presented to contextualize the study application. Section 4 outlines the modeling strategy adopted with respect to both the construction of the CI and the CI model structures. The data is described in the following section and the results of model estimation are presented and discussed in Sections 6 and 7. The final section offers some concluding remarks.

\section{Product Differentiation and Movie Conventionality: A Brief Retrospect}

In general terms, a CI for a cultural experience good may be defined,

$$
C L_{i}=\frac{\sum_{i=n}^{n} g_{i}}{n}
$$

Where $p_{i}$ is the number of entities (venues or performing companies) in a sample under scrutiny showing/performing a given type of cultural good in a given time period and $n$ is the total number of that type of cultural good shown (or performed) in the same given time period. Essentially, it corresponds to the average number of entities in which each given cultural good 
shown or performed by a given entity is shown/performed elsewhere in that given time period. It is a metric that has been widely used to formally analyze the repertoire diversity or degree of product differentiation by theaters and orchestras (Neligan, 2006; O’Hagan and Neligan, 2005; Pierce, 2000; Dowd et al., 2002). The usual second stage in such analyses is to estimate a singleequation CI function using OLS regression. For example, the typical array of right hand side variables for theaters pertain to, inter alia, the proportion of subsidy and subscription income of a given theater venue or performing company, a political index of the government subsidy awarders, some simple measure of competition (e.g. number of public/private theaters in the relevant municipality), a range of venue-specific characteristics, population size and a range of socio-economic variables for the municipality in which the venue lies.

Hitherto this approach has not been used to analyze product differentiation in commercial theater (e.g. New York Broadway, London West End) or cinemas/movie theaters of any kind. With respect to movie theaters, key differences with the dramatic theater studies concern (i) the degree of reliance on commercial revenue streams and (ii) that while theater (or symphony orchestra) senior management actually oversee the selection, production and performance of repertoire, this may not be the case for a given movie theater. This latter point suggests the need for some different arguments in a movie theater CI function and the need to be informed by a corpus of economic theory not largely contingent on the theme of expected and revealed public sector preferences.

While many do exist, most individual movie theaters are not independent firms or entities. Rather, they are outlets in a multiple chain of movie theaters owned by an exhibitor firm. Local management at each outlet typically has very limited discretion over the 'slate' of newly released films that are shown. Decision-making by exhibitor firms may also constrained by means of high equity cross-ownership or full forward vertical integration between distributor and exhibitor firms. Even where this is not the case exhibitor firms still have to buy bundles of films (block-booking) negotiated with very complex contractual arrangements from movie distributor companies. In accordance with profit maximizing economic theory, each bundle will typically contain some films expected to be high earners and some low earners (Stigler 1968, Adams and Yellen, 1976, Dansby and Conrad, 1984, Salinger, 1995).

The contracts feature various box office and movie theater concessions (food, drink etc) revenue apportionment formula and possibly 'holdover' clauses mandating extensions 
to film screening days in the event of particular box office targets being achieved. Orstein (1995) and Orbach (2004) provide a detailed analysis of the contractual frameworks governing movie theater operations. The latter work also provides useful insights to help account for the persistent lack of price competition in this sector, particularly given that history shows box office pricing was not always predominantly uniform. He does not attribute this to the efficient market hypothesis, but rather to 'pressure' from distributors seeking to minimize a range of demand and supply side risks. Shaked and Sutton (1982) provide theoretical support for this view that firms will use vertical product differentiation to relax price competition.

However it was achieved, the power of distributors and exhibitors to ensure nonprice competition now dominates market conduct, renders the degree of product differentiation and its domains or levels (i.e. film-based, movie theater environment-based), to be a more significant practical focus of economic enquiry. Lancaster (1990) provides a panoramic survey of the general literature and from the individual firm's perspective identifies three approaches to analyzing product variety by multiproduct firms. The first relates to the production side and focuses on cost advantages from joint production and economies of scope. The second relates to demand side concerns in balancing the increased revenue from greater product variety against the loss of scale economies in the production of each variant. The third relates to the deployment of product variety as a form of strategic preemption in the product space to achieve entry deterrence objectives.

The development, diffusion and rate of growth of the multiplex phenomenon could potentially be viewed in the light of all three of these reasons, but so could the vertical or quasi-vertical integration of distributors and exhibitors, increasing market concentration and possibly the heavy reliance on particular 'proven' plot formulas, 'date movie' appeal and star actors/actresses.

Hotelling (1929) first set out the idea of firms competing on more than one level - in his case price and location. The upshot of the basic proposition was that the equilibrium competitive location for two firms operating in a linear market with distinct terminal boundaries and uniformly distributed customers was to be as close as possible together without actually colliding. As Lancaster (1990) noted, “...beyond pure geographical location, the proposition is concerned with the degree of differentiation rather than the number of goods, answering the question: if there are two firms in the market, will their best strategy be to choose products which 
are very similar or very different?” [p197]. So emerged the so-called Principle of Minimum Differentiation.

Yet in subsequent years his equilibrium results were heavily challenged and found not to hold for cases of more than three firms and when various other assumptions were relaxed or modified. The revision by D'Aspremont et al (1979) suggesting quadratic rather than linear transport costs suggested a maximum rather than minimum differentiation equilibrium outcome. Best (1998) however, suggested that imperfect information about the vertical (quality) characteristics of goods (films) reduces distributors/exhibitors incentives for horizontal product differentiation (other films/genres) and thus leading to minimum product differentiation. In spatial terms, the implication is that firms (movie theaters) will tend to choose head-on completion by agglomeration at a given location. This means that consumers can incidentally benefit from imperfect information concerning product (film) quality.

Typically these studies tend to assume, as Hotelling did in his original work, that consumers are uniformly distributed. When this particular assumption was dropped, De Palma et al (1985) identified renewed theoretical support for the Minimum Differentiation Principle. Hence, non-uniformly distributed consumers in geographical and/or product characteristics space (i.e. consumer heterogeneity in space and tastes) provide some theoretical basis to justify expectations of a high CI score in the context of movie theater exhibition.

Chisholm and Norman (2004) investigated the degree to which the Minimum Differentiation Principle extends to location choices by multi-product firms of different sizes supplying differentiated goods to consumers with heterogeneous tastes. They found that multiproduct firms disperse their products if consumer heterogeneity is low or distance between markets is high.

\section{The Movie Exhibition Sector in Italy}

An important and motivating focus for this study is the current supply structure of cinemas and screens in Italy. Up to a few years ago, the opening of a new cinema was subject to stringent public regulations. In fact, the regulation resulted in a severe rationing of openings and in the progressive ageing of supply: the vast majority of cinemas were single screen, often with historical locations in downtown areas. In recent years the sector was liberalized. The changes resulted in the opening of many multi screen cinemas (from 5 to 7 screens) or 
multiplexes (8 or more screens) at the expenses of smaller single screen structures ${ }^{1}$. As shown in Table 1, the total number of cinema remains more or less constant (-2.7\%) while the number of screens rose significantly (+9\%). The increasing proportion of new-build cinemas can be shown to be connected with increased quality in terms of the viewing experience (particularly in term of comfort of the seats, sight lines, etc) as well the introduction of up-to-date marketing and organizational techniques. For example, the number of cinemas closed in July and August (a common practice for small single family-owned and run single screen cinemas) has sharply reduced.

Some supporting evidence is provided in Table 1 showing that admissions to single screen cinemas in 2004 was slightly above $20 \%$ but that two years later the figure dropped to $15 \%$. The redistribution of cinema goers seems to be in the favor of multiplexes.

Table 1 about here

On the basis of such data it is possible to assert that the average size of an Italian cinema has slightly increased - from 2.2 to 2.5 screens per cinema during the period 2004-2006. The increase, however, comes in only in part from the increased size of individual cinema complexes (where the average number of screens has risen by $6.7 \%$, from 4.35 to 4.65 ). Of principal importance has been the increase in the market share of the larger types of cinemas (an $8.6 \%$ increase, from 465 to 505 ). The overall effect has been a $15.6 \%$ increase in the number of screens in the larger cinemas which overshadows the 9.6\% drop in the number of single screen cinemas.

As a consequence of a decrease in the total number of admissions and of the increase in the number of screens, the average attendance per screen dropped by just under $14 \%$ over the three years considered. Further interesting trends can be discerned if the data is disaggregated by cinema size. The average admission for single screen cinemas has collapsed dramatically (-26\%), whereas the drop for multi-screen cinemas and megaplexes, albeit significant, remains limited to $-15 \%$ and $-13 \%$, respectively. These developments have evolved

\footnotetext{
${ }^{1}$ This trend is portrayed in the movie "Nuovo Cinema Paradiso" by G. Tornatore that won the 1989 Academy Award (Oscar) for Best Film in a Foreign Language.
} 
at a different pace within the various regions of Italy. The data shows that in the more urbanized Northern area, the extent of the decline of single screen cinemas has been so thorough that they almost rendered extinct ${ }^{2}$, while in the South this process of transformation is lagging behind that of the North. In the Central regions (with the notable exception of Rome) a more 'intermediate' position $^{3}$ can be discerned.

From the perspective of this study's focus of enquiry, the identification of different business strategies and outcomes associated with large and small cinema establishments is of central importance. This enables some assessment of the extent to which cinemas of different size exhibit different conventionality indices. This can be quantified by computing CIs per screen and per cinema (thereby aggregating the eight or more screens of a multiplex into a single "average” screen).

Unsurprisingly, single screen cinemas are also losing importance in terms of admissions. Table 2 shows that the proportion of the smaller cinema establishments, even if still sizeable, is decreasing steadily, from 21\% in 2004 to 15\% in 2006. For this segment, the drop in terms of attendance per screen is even more dramatic: from 26,591 tickets sold in 2004, to 19,763 in 2006 , with a $25.6 \%$ decrease.

As for the type or genre of movies, Italian preferences seem similar to those of the rest of the Europe. US movies dominate the box office and most of the distributors are subsidiaries of the American based majors. The market share for national films fluctuates around $22-25 \%$ of the total number of admissions, with some very temporary increases in the case of a few particularly successful Italian hits (Table 2).

Table 2 about here

Regardless of movie origins, cinema consumption in Italy has been and still remains high. It is, by and large, the most popular activity among the range of performing arts. Figure 1 presents the pattern of participation over recent years. It is immediately apparent that within a broadly stable picture for the other performing arts, there is some evidence of increasing cinema going.

\footnotetext{
${ }^{2}$ Several single screen cinemas were transformed into multiplexes.

${ }^{3}$ Tables have not shown for the sake of brevity but are available upon request from the authors.
} 
Figure 1 about here

\section{The Model}

This paper empirically analyzes the impact of several factors on the conventionality index (Neligan, 2006; O’Hagan and Neligan, 2005; Pierce, 2000), CI, defined in the specific context of cinema, as follows:

$$
C I_{i}=\frac{\sum_{i=1}^{n} c_{i}}{n}
$$

Where $c_{i}$ is the number of programming (screening) days by the cinema in question, and $n$ is the total number of movies screened by that cinema in the analysed period.

In explaining variations in a CI, demographic and economic variables are used to identify demand-side indicators that are expected to reflect local characteristics for specific productions (Pierce, 2000). The size of the market, measured by population, is expected to influence positively the conventionality to the extent that longer screening days are necessary to satisfy higher and more stable levels of demand. To this end, it can potentially be useful to adopt a spatial weight matrix approach (Werck and Heyndels, 2007). This involves multiplying the number of inhabitants in municipality $j$ in Province $k$ with a spatial weight matrix relevant to cinema $i$, whose elements are equal to one if municipality is part of the relevant market for cinema $i$ and 0 otherwise. Up to three different specifications were considered, ${ }^{4}$ though this study uses a contiguous population specification, pop2. It might reasonably be expected that a cinema based in a metropolitan area would have scope to host more specialized repertoire than a cinema of equal size in a small town, due to audience segmentation and market niches, over which they enjoy some market power (Neligan, 2006). Further, the influence of word of mouth mechanisms might require longer periods among larger populations, and therefore contribute to this result.

Additionally, the age structure represents a potentially important feature of movie

\footnotetext{
${ }^{4}$ Three different specifications were used. In the first it is assumed that the relevant market is limited to the municipality in which the cinema is located. In the second specification the relevant market is extended to enclose contiguous municipalities. Finally, in the third specification it is assumed that the relevant market coincides with the whole Province.
} 
turnover. The percentage of the population aged up to fourteen, age14 is a market segment whose characteristics are expected to differ from the more mature movie goers (aged 15-64). Younger people (and those with less 'established' movie going behavior) may be strongly influenced by fads and be subject to different time constraints, etc. As a consequence, the overall effect on movie turnover is complex and the expected sign cannot readily be predicted in advance.

Following the empirical literature on conventionality (Neligan, 2006; O’Hagan and Neligan, 2005; Heilbrun, 2001 Pierce, 2000), per capita income, gdp, is introduced as a potential explanatory variable. Since cinema consumption is expected to increase with income (Sisto and Zanola, 2008), it is likely to register a lower movie turn over.

Finally, we include a dummy for multiplexes, multiplex, to catch structural aspects of the market. Since multiplexes screen blockbusters, whose demand may be more durable than less commercial movies, they are expected to show a lower level of movie turnover.

In summary the model being tested in this paper is as follows:

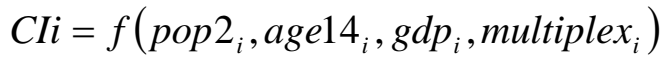

\section{Data}

The analysis covers a cross section of three Italian regions in 2006, which have been considered by Italian cinema industry analysts as representative of the Italian market ${ }^{5}$. These are, namely, Piemonte, Lazio and Campania. CIs are constructed using data provided by Cinetel, a company specializing in the collection and compilation of motion picture industry data. Per capita income data are drawn from the Minister of Economy's Dichiarazione dei redditi presentate dalle persone fisiche nel 2005. Data on per capita population income derives from the Istat's (2006) Annual Statistics. Structural data has been derived from Cinetel. Table 3 shows the basic descriptive statistics for the dependent variable CI and the key independent variables.

\footnotetext{
${ }^{5}$ As suggested before, the adjustments in the different regions of Italy evolved at a different pace. Our sample is representative of all the situations: Piemonte is in the North of Italy, Lazio in the Centre and Campania in the South.
} 
Insert Table 3 about here

\section{Results}

As indicated in the previous section, the dependent variable is the conventionality index, calculated as the ratio between programming days and the total number of movies screened. However, two distinctive definitions are considered: (i) single CIs, calculated for each screen (and in this case multiplexes are considered as several different screens), or (ii) full CIs, in which case multiplexes are considered as a unique weighted screen.

Before proceeding we test for heteroskedasticity of residuals. Both the White's test and the Breusch-Pagan test have been performed. The null of homoskedasticity is rejected at 1 per cent level so that heteroskedasticity seems to be a problem in our sample. To this aim, the standard errors are adjusted to provide heteroskedastic consistent standard errors using a heteroskedasticity consistent regression matrix.

Normality of residuals is required for the $\mathrm{t}$ and $\mathrm{F}$ statistics to be valid. Kernel density estimation indicated problems with the normality of residuals. Additionally, the ShapiroWilks test for normality rejects the null hypothesis of normality at the 1 per cent level. Having concluded that conventionality is not normally distributed, we select an appropriate transformation of variable to convert it into a normally distributed one. Results indicate that the $\log$ transformation is the most appropriate.

Regression results of the single CI are presented in Table 4. Standard errors and variance-covariance matrices of the log-specification of Equation (3) has been computed by using the Huber/White/sandwich heteroskedasticity-robust procedure.

Insert Table 4 about here

In testing for the correct model specification, a link test was undertaken. This test computes a new regression model using as predictor variables the risk score from the original model plus its square (quadratic term). If the additional quadratic term is significant, 
there is evidence of model misspecification. In our case, the estimated model does not display a significant quadratic term, providing no evidence of incorrect model specification when per capita income is excluded.

Contiguous population displays a positive sign at the 1 per cent significance level. Consistent with prior expectations, larger contiguous areas (рор2) feature higher conformity. Regarding the population structure (p14), the coefficient turns out to display a negative sign significant at the 5 per cent level. A potential explanation may be linked to the peculiar characteristics of this market, where teenagers are perhaps more prone to faddy consumption and, consequently, a higher movie turnover. Per capita income is positive and statistically significant at 1 per cent level. A 1 per cent increase in income level will increase conventionality at 0.34 per cent, suggesting the existence of an income effect on the size of the market.

Focussing on the structural variables, the multiplex coefficient (multiplex) is statistically significant at the 1 per cent and shows a positive relationship with conventionality. This result sheds some light on the scheduling characteristics of multiplexes, which tend to display a lower turnover of movies due to higher audience numbers. ${ }^{6}$

Given that data on single screens are used in this study, it is not possible to directly capture the distinctive strategies of multiplexes in aggregate. Single CIs treat multiplexes as several different screens, where the programming strategy for a given screen is totally independent to those of the other screens (even though part of the same multiplex).

With this shortcoming in mind, the previous analysis has been extended to the full CI sample, where basic descriptives are shown in Table 5.

\section{Insert Table 5 about here}

Table 6 shows the regression results of the Huber/White/sandwich heteroskedasticity-robust procedure for the full CI sample. Due to multicollinearity with population, the dummy variable for provincial capital was dropped. Again, it was found that a log transformation helped to make conventionality more normally distributed and no evidence of

\footnotetext{
${ }^{6}$ We also check for the existence of some regional idiosyncratic effect by introducing regional dummy variables. However, they are not statistically significant confirming the substantial homogeneity of the sample.
} 
misspecification emerged from the link test.

Insert Table 6 about here

In the case of the full CI sample, the Huber/White/sandwich heteroskedasticityrobust regression seems to suggest the same picture that emerged from the single CIs sample: coefficients display the same signs as in Table 4, and are statistically significant, with the only exception of the multiplex coefficient. In this case, conventionality appears to be analogous within the sample for both single screen and multiplexes. As a consequence, the dummy for multiplexes does not show any specific effect.

\section{Concluding Remarks}

This paper has sought to analyze the development of movie programming in Italy. The cinema sector in Italy is undergoing a major transformation. Small single screen cinemas are of diminishing importance but remain, for the time being, a significant element in the cinema exhibition sector. Moreover, cinemas tend to be located in a number of major cities, or close to them. On the basis of such cinema characteristics, more homogeneous programming might be expected to be an observable feature of the market. Thus the central research question relevant to this study and guiding the empirical work has been to identify whether developments in the Italian cinema sector has led to an increasingly homogeneous or heterogeneous supply of movies?

In order to answer to this question, a conventionality index approach has been adopted. The conventionality index is a metric that has been widely used to formally analyze the repertoire diversity or degree of product differentiation by theaters and orchestras. Yet to the best of our knowledge, it is the first time that this approach has been applied to a principally private sector market, such as the case of cinema.

The analysis was conducted on a sample of three Italian regions in 2006 (Piemonte, Lazio and Campania), considered by industry experts as representative of the full Italian market. The main conclusion that can be drawn from this study is that conventionality 
dropped slightly when the index was computed for multiplexes considered as a unique weighted screen relative to the single screen case.

However, when the main determinants of the conventionality indexes were analyzed, the effect of the multiplexes was actually to increase the conventionality of the supply, taking into account the effect of other explanatory variables. Additionally, conventionality is also increased by both income and market dimensions: the greater the income and the more extensive is the spatial dimensions of the market, the higher is the level of conventionality. 


\section{References}

Adams WJ, Yellen JL. 1976. Commodity Bundling and the Burden of Monopoly. Quarterly Journal of Economics 90: 475-98.

Bester H. 1998. Quality Uncertainty Mitigates Product Differentiation. RAND Journal of Economics 29: 828-844.

Chisholm DC, Norman G. 2004. Heterogeneous Preferences and Location Choice with MultiProduct Firms. Regional Science and Urban Economics 34: 321-339.

Chisholm DC, McMillan MS, Norman G. 2006. Product Differentiation and Film Programming Choice: Do First Run Movie Theaters Show the Same Films? NBER WP 12646.

Collins A, Hand C, Ryder A. 2005. The Lure of the Multiplex? The Interplay of Time, Distance and Cinema Attendance. Environment \& Planning A 37: 483-501.

Dansby RE, Conrad C. 1984. Commodity Bundling, American Economic Review (Paper and Proceedings) 74: 377-381.

D’Aspremont C, Gabszewicz JJ, Thisse J-F. 1979. On Hotelling's Stability in Competition. Econometrica 17:1145-1151.

De Palma A, Ginsburgh V, Papageorgiou, Y, Thisse J-F. 1985. The Principle of Minimum Differentiation Holds Under Sufficient Heterogeneity Econometrica 53: 767-781.

Dowd TJ, Liddle K, Lupo K, Borden A. 2002. Organizing The Musical Canon:

The Repertoires of Major U.S. Symphony Orchestras, 1842 to 1969. Poetics 30: 35-61.

Hubbard P. 2000. Save our Screens? Town and Country Planning 69: 299-301. 
Hubbard P. 2002. Screen-shifting: Consumption, 'Riskless Risks' and the Changing Geographies of Cinema. Environment and Planning A 34: 1239-1258.

Neligan A. 2006. Public Funding and Repertoire Conventionality in the German Public Theatre Sector: An Econometric Analysis. Applied Economics 38: 1111-1121.

O’Hagan J, Neligan A. 2005. State Subsidies and Repertoire Conventionality in the Non-Profit English Theatre Sector: An Econometric Analysis. Journal of Cultural Economics 29: 35-57.

Orbach BY. 2004. Antitrust and Pricing in the Motion Picture Industry. American Law and Economics Association Annual Meetings, Working Paper 40, 1-45. http://law.bepress.com/alea/14 $/$ art40

Ornstein SI. 1994. Motion Picture Distribution, Film Splitting and Antitrust Policy. Hastings Communications and Entertainment Law Journal 17: 415-444.

Pierce JL. 2000. Programmatic Risk-Taking by American Opera Companies. Journal of Cultural Economics 24: 45-63.

Lancaster K. 1990. The Economics of Product Differentiation: A Survey. Marketing Science 9: 189-206.

Salinger MA. 1995. A Graphical Analysis of Bundling. Journal of Business 68: 85-98.

Shaked A, Sutton J. 1982. Relaxing Price Competition Through Product Differentiation. Review of Economic Studies 49: 3-13.

Sisto A, Zanola R. 2008. Cinema Attendance in Europe, Applied Economics Letters (forthcoming)

Stigler GJ. 1998 A Note on Block Booking, In: The Organization of Industry, GJ Stigler (ed). 
Homewood: R. D. Irwin.

Werck K, Stultjes M, Grinwis P, Heyndels B. 2007. Budgetary Constraints and Programmatic Choices by Flemish Subsidized Theatres Applied Economics (forthcoming)

Wojan TR, Lambert DM, McGranahan DA. 2007. Emoting with their Feet: Bohemian Attraction to Creative Milieu. Journal of Economic Geography 7: 711-736.

Wolinsky A. 1985. Product Differentiation with Imperfect Information. Review of Economic Studies 51: 53-61. 
Table 1. The structure of the Italian movie distribution industry

$\begin{array}{lcccc} & \text { Year } & \begin{array}{c}\text { Single } \\ \text { screen }\end{array} & \text { Multiplex } & \text { Total } \\ N^{\circ} \text { of cinemas } & 2004 & 778 & 465 & 1,243 \\ & 2005 & 779 & 496 & 1,275 \\ & 2006 & 704 & 505 & 1,209 \\ N^{\circ} \text { of screens } & & & & \\ & 2004 & 778 & 2024 & 2,802 \\ \text { Average screen per cinema } & 2005 & 779 & 2237 & 3,016 \\ & 2006 & 704 & 2346 & 3,050 \\ & 2004 & 1 & 4,352688 & 2,254,224 \\ & 2005 & 1 & 4,510081 & 2,365,490 \\ & 2006 & 1 & 4,645545 & 2,522,746\end{array}$

Source: Cinetel

Table 2. Movie attendance in Italy, 2004-2006

$\begin{array}{lcccc} & & \begin{array}{c}\text { Single screen } \\ \mathbf{( \% )}\end{array} & \begin{array}{c}\text { Multiplex } \\ \mathbf{( \% )}\end{array} & \text { Total } \\ \text { Attendance } & 2004 & 21,13 & 78,87 & 97,927,192 \\ & 2005 & 17,57 & 82,57 & 90,641,603 \\ & 2006 & 15,1 & 84,9 & 92164739 \\ \text { Average attendance } & 2004 & 26591 & 38159,67 & \\ \text { per screen } & 2005 & 20444 & 33456,76 & 34,949 \\ \text { Source: Cinetel } & 2006 & 19763 & 33353,74 & 30,053 \\ & & & & \end{array}$


Table 3. Summary statistics (single CI sample)

\begin{tabular}{|l|c|c|c|c|c|}
\hline Variable & Obs & Mean & Std. Dev. & Min & Max \\
\hline single CI & 870 & 10.40179 & 4.2733 & 1.583333 & 40.08333 \\
\hline pop2 & 870 & $1,296,396$ & $1,268,905$ & 11,447 & $3,113,130$ \\
\hline p14 & 870 & .1436967 & .0201929 & .1089435 & .1828786 \\
\hline gdp & 870 & $22,480.63$ & $3,102.12$ & 15,603 & 27,463 \\
\hline multiplex & 870 & .8563218 & .3509649 & 0 & 1 \\
\hline
\end{tabular}

Table 4. Regression results (single CI sample)

\begin{tabular}{|l|c|c|c|c|}
\hline Single CI & Coef. & Robust Std. Err. & t & Beta \\
\hline pop2 & .0794262 & .0099685 & 7.97 & .3426394 \\
\hline$p 14$ & -1.678658 & .7046662 & -2.38 & -.0898779 \\
\hline gdp & .3497385 & .1117659 & 3.13 & .129156 \\
\hline multiplex & .13438 & .0445128 & 3.02 & .129156 \\
\hline cons & -2.149166 & 1.08023 & -1.99 & .1250516 \\
\hline & & & & \\
\hline Number obs. & 870 & & & \\
\hline F(7,861) & 58.60 & & & \\
\hline R-squared & 0.2392 & & & \\
\hline Link test & -.6063868 & & & \\
\hline Mean VIF & 1.70 & & & \\
\hline
\end{tabular}


Table 5. Summary statistics (full CI sample)

\begin{tabular}{|l|c|c|c|c|c|}
\hline Variable & Obs & Mean & Std. Dev. & Min & Max \\
\hline full CI & 282 & 9.89576 & 5.361723 & 1.583333 & 40.08333 \\
\hline pop2 & 282 & $1,036,370$ & $1,214,768$ & 11,447 & $3,113,130$ \\
\hline p14 & 282 & .1436448 & .0220754 & .1089435 & .1828786 \\
\hline gdp & 282 & $22,240.87$ & $2,945.753$ & 15,603 & 27,463 \\
\hline multiplex & 282 & .5602837 & .497235 & 0 & 1 \\
\hline
\end{tabular}

Table 6. Regression results (full CI sample)

\begin{tabular}{|l|c|c|c|c|}
\hline Full CI & Coeffient. & Robust Std. Err. & t & Beta \\
\hline pop2 & .0943814 & .0275036 & 3.43 & .3280474 \\
\hline$p 14$ & -2.472265 & 1.582562 & -1.56 & -.1157037 \\
\hline$g d p$ & .7168488 & .2913231 & 2.46 & .2016467 \\
\hline multiplex & .0606911 & .0521557 & 1.16 & .0639781 \\
\hline cons & -5.877908 & 2.790462 & -2.11 & \\
\hline & & & & \\
\hline Number obs. & 282 & & & \\
\hline F(6,275) & 27.28 & & & \\
\hline R-squared & 0.2699 & & & \\
\hline Link test & .4368184 & & & \\
\hline Mean VIF & 1.89 & & & \\
\hline
\end{tabular}


Figure 1. Participation in performing arts events in Italy (1993-2006)

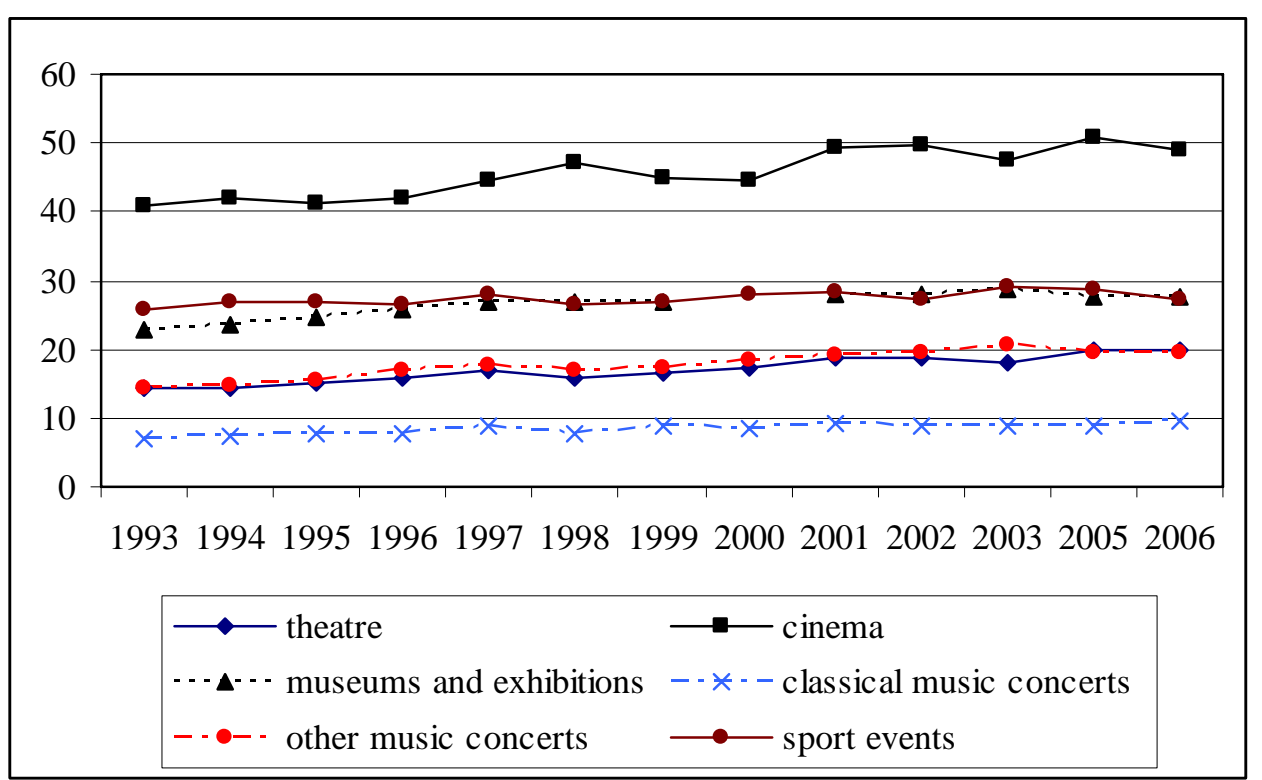

Source: Istat.

Note: data for 2004 are not available 